\title{
¿QUO VADIS ENERGÍA RENOVABLE? EL ESTADO DE LA CUESTIÓN EN ESPAÑA
}

\author{
ANTONI GIFREU FONT \\ Licenciado en Ciencias Ambientales y Máster en Derecho Ambiental. \\ Doctorando en la Universitat Rovira i Virgili \\ gifreu@hotmail.com
}

Recibido: 18 de junio de 2015 / Aceptado: 29 de septiembre de 2015

RESUMEN: El artículo muestra la situación de las energías renovables a nivel mundial, europeo y del Estado español, las fortalezas y debilidades de estas, y el revuelo que crea la nueva propuesta sobre el RD de autoconsumo y la posición del Estado español hacia las energías renovables.

RESUM: L'article mostra la situació de les energies renovables a nivell mundial, europeu i de l'Estat espanyol, les fortaleses i debilitats d'aquestes, i l'enrenou que crea la nova proposta sobre el RD d'autoconsum i la posició de l'Estat espanyol envers les energies renovables.

\begin{abstract}
The article shows the situation of renewable energy on a global level, European and the Spanish State. The strengths and weaknesses of these. The stir created by the new proposal on the RD subsistence and position of the Spanish State to renewables.
\end{abstract}

PALABRAS CLAVE: Energías renovables — Derecho español — Desarrollo sostenible - Autoconsumo energético 
PARAULES CLAU: Energies renovables - Dret espanyol - Desenvolupament sostenible — Autoconsum energètic.

KEY WORDS: Renewable energies — Spanish Law — Sustainable development — Selfsupply.

SUMARIO: I. Introducción. II. Energías renovables: estado de la cuestión. 1. El contexto internacional. 2. La Unión Europea. III. El Estado español. 1. Estado de la cuestión. 2. La contribución de las energías renovables en el Estado español. 3. Retos de las energías renovables en el Estado español. IV. A modo de conclusión. V. Bibliografía.

\section{INTRODUCCIÓN}

La primera evolución que conoció la especie humana fue la neolítica ${ }^{1}$, donde se introdujo una nueva manera de trabajar la piedra y se empezaron a practicar la agricultura y la ganadería en lugares y fechas dispares en nuestro planeta. La Revolución Industrial —en sus dos grandes manifestaciones: 1750-1840 y 1880-1914- encarna una nueva fase evolutiva en la que el trabajo manual y el uso de la tracción animal, ejes de la economía productiva de entonces, fueron substituidos por máquinas de vapor y motores eléctricos.

Este cambio de modelo energético inicia un ciclo de deterioro medioambiental y de degradación del paisaje que se ha acelerado durante el período postindustrial como consecuencia del incremento del consumo de las energías convencionales, que, al no ser energías limpias, tienen grandes repercusiones en el medio ambiente. Pero algunos estudiosos consideran que este modelo energético, económico y productivo está llegando a su fin y que asistimos a una tercera revolución industrial ${ }^{2}$, la científico-técnica, en la que

\footnotetext{
${ }^{1}$ El arqueólogo australiano Vere Gordon Childe fue el primero en acuñar el término evolución neolítica; también es conocido por sus teorías sobre el desarrollo de las civilizaciones prehistóricas.

${ }^{2}$ Jeremy RIFKIN señala en La sociedad de coste marginal cero, Paidós Ibérica, 2014, que estamos inmersos en la tercera revolución industrial, la de Internet y la energía renovable. En esta misma línea, Andrea Benassi, secretario general hasta 2011 de la Asociación Europea del Artesanado y de la Pequeña y Mediana Empresa (UEAPME), señalaba en Bruselas, el 1 de febrero de 2010, durante una reunión de pequeñas y medianas empresas, que todos los programas en la UE debían ser rediseñados para hacer realidad la tercera revolución industrial. En este sentido, el intelectual y escritor peruano Virgilio Roel Pineda, en La tercera revolución
} 
las energías alternativas, clasificadas como verdes por su escaso potencial contaminante, juegan un papel esencial en la configuración del modelo productivo ${ }^{3}$. Estas energías renovables ${ }^{4}$, por su bajo impacto ambiental y su capacidad de regeneración, se consideran una alternativa verde ya que se obtienen a partir de recursos naturales que se reponen constantemente a una velocidad muy superior a la de las energías tradicionales. Por lo tanto, ¿pueden estas energías contribuir positivamente al desarrollo económico, social y ambiental del Estado español?

Antes de contestar tan importante cuestión, me gustaría seguir el esquema de SALINAS (2014, p. 23) para justificar por qué servidor, ambientólogo, no procedente de la rama del derecho, realizo un ensayo en la Revista Catalana de Dret Ambiental. La misión de los especialistas en el ámbito de las energías renovables es analizar la realidad social, ambiental y económica para que así el jurista cree un régimen jurídico que ordene las energías renovables ${ }^{5}$. Tal régimen jurídico no sería útil de no existir intereses, conflictos o incertidumbres. Se pueden, y se deben, regular aspectos ambientales desde una perspectiva preventiva, y por eso las regulaciones deben ser modificadas en el tiempo sobre la base de conceptos como, por ejemplo, las mejores técnicas disponibles. Esta actualización constante obliga a las ciencias naturales a ir un paso por delante de las jurídicas y prever qué pasará, por ejemplo, mediante informes del Grupo Intergubernamental de Expertos sobre el Cambio Climático. En definitiva, ciencia y derecho están ligados, ambos se equivocan constantemente y se necesitan.

industrial y la era del conocimiento, UNMSM, Lima, 1998, enmarca las energías renovables en los grandes procesos e innovaciones de la tercera revolución industrial.

${ }^{3}$ CRUZ PEÑA, Juan. (2014, septiembre). Cómo será la economía del futuro. J Rifkin: “El capitalismo estará abocado a desaparecer en 35 años". Recuperado en junio de 2015, de http://www.finanzas.com/noticias/economia/20140922/rifkin-capitalismo-estara-avocado-2758208.html.

${ }^{4}$ Son aquellas fuentes que se pueden regenerar en un período corto de tiempo. Los diferentes tipos enumerados en el artículo 2 de la Directiva 2009/28/CE son: la energía eólica, solar, aerotérmica, geotérmica, hidrotérmica y oceánica, hidráulica, biomasa, gases de vertedero, gases de plantas de depuración y biogás. DOMINGO (2000, p. 29) las define como: "Aquellas fuentes primarias de energía que, de forma periódica, se renuevan a través de ciclos naturales, por lo que se pueden considerar inagotables, es decir, se renuevan de forma continua, en contraposición a los combustibles fósiles de los que existen unas determinadas reservas que se agotarán en un periodo de tiempo determinado, el hombre puede aprovechar las fuentes energéticas renovables de energía mediante su transformación en energía útil”.

${ }^{5}$ SALINAS ALCEGA, S., El cambio climático: entre cooperación y conflicto, Aranzadi, 2014, p. 23. 
Pero volviendo a la pregunta anterior, el presente estudio pretende eliminar algunos interrogantes a esta cuestión y resolver parcialmente cuál puede ser la contribución de las energías renovables en el Estado español interpretando el recorrido de las políticas internacionales, europeas y del Estado en materia de energías renovables, aportando datos económicos y de desarrollo de esta tecnología a nivel mundial, mostrando algunas ciudades europeas que apuestan por las energías renovables, y valorando y analizando los retos y las contribuciones de las energías renovables en el Estado español. Y todo ello desde una perspectiva ambiental, con datos económicos y una orientación que pretende ser útil para las ciencias jurídicas.

Pero ¿qué y cuáles son estas energías limpias?

Son las fuentes de energía renovable. De entre estas, las tecnologías más explotadas y que pueden ser de mayor ayuda para garantizar el desarrollo económico del Estado español son las siguientes:

- Energía solar fotovoltaica: genera la electricidad mediante células fotoeléctricas que al recibir radiación solar se excitan y provocan saltos, generando una diferencia potencial en sus extremos.

- Energía solar termoeléctrica: se basa en la producción de vapor a partir de un fluido sometido a altas temperaturas. A su vez, dicho vapor genera electricidad por medio de un alternador accionado por una turbina ${ }^{6}$.

- Energía eólica: se obtiene a partir del movimiento de las masas de aire, que se transforma en energía eléctrica mediante aerogeneradores.

- Energía hidráulica: se obtiene con la caída del agua a un nivel inferior, lo que provoca el movimiento de ruedas hidráulicas o turbinas que generan un movimiento de rotación que se transforma en energía por medio de generadores eléctricos.

- Biomasa: aprovechamiento de la materia formada en algún proceso biológico mediante la combustión o para la obtención de gas.

\footnotetext{
${ }^{6}$ ROLDÁN VILORIA, J., Energías renovables: lo que hay que saber, Paraninfo, Madrid, 2013, pp. 74-75.
} 
- Energía geotérmica: consiste en la inyección de agua en zonas de alta temperatura para que, una vez transformada en gas, se eleve hacia una turbina de vapor que transforma con un alternador el movimiento rotativo del gas en corriente eléctrica ${ }^{7}$.

- Energía mareomotriz: utiliza el gradiente de las mareas, es decir, la diferencia de altitud, para producir energía eléctrica de forma similar a la energía hidráulica.

- Energía undimotriz: se obtiene aprovechando el movimiento y la fuerza de las olas.

- Energía de gradiente térmico oceánico: mediante la diferencia potencial de temperatura del agua del mar en base a su profundidad, se cambia de estado líquido a vapor un fluido que, al elevarse, mueve una turbina, y con un alternador se genera corriente eléctrica.

Esta clasificación —extraída en parte de ROLDÁN VILORIA, “Energías renovables...”, cit., p. 48 - de las fuentes renovables muestra nueve fuentes de energía renovable de un sector que va diversificándose y evolucionando.

Pero ¿cómo estas fuentes de energía renovable serán capaces de satisfacer la demanda creciente de energía y preservar el medio ambiente a través de una mínima alteración de este?

En mi opinión, a través de políticas energéticas que favorezcan priorizar soluciones que armonicen el necesario desarrollo económico del país con la protección del medio ambiente, dos parámetros que, a día de hoy, constituyen la base del desarrollo sostenible ${ }^{8}$, entendido como la interrelación entre medio ambiente, desarrollo económico y desarrollo social, como han puesto de manifiesto las Naciones Unidas:

La defensa y el mejoramiento del medio humano para las generaciones presentes y futuras se ha convertido en meta imperiosa de la humanidad, que ha de perseguirse al

\footnotetext{
${ }^{7}$ La energía geotérmica es muy utilizada en Islandia; su capital, Reikiavik, cuenta con cinco centrales geotérmicas que producen electricidad y agua caliente para proveer de calefacción a toda Islandia. En 2011, el $84 \%$ de la energía primaria usada en este país se creó en plantas de energía renovable; el 66\% era geotermal.

${ }^{8}$ GONZÁleZ PÉREZ, J., Comentarios a la ley de suelo, Civitas Ediciones, Madrid, 2015, p. 131.
} 
mismo tiempo que las metas fundamentales ya establecidas de la paz y el desarrollo económico y social en todo el mundo, y de conformidad con ellas 9 .

Como se pone de manifiesto en el artículo 3.3 del Tratado de la Unión Europea:

Obrará en pro del desarrollo sostenible de Europa basado en un crecimiento económico equilibrado, $[\ldots]$ una economía social $[\ldots]$ y en un nivel elevado de protección y mejora de la calidad del medio ambiente.

Este desarrollo sostenible necesita de un sustrato en forma de energías renovables para desarrollar su actividad. Por lo tanto, es necesario ver qué dice la normativa urbanística respecto a cómo debe ser este crecimiento. En este sentido, el artículo 3 del Decreto Legislativo 1/2010, de 3 de agosto, por el que se aprueba el texto refundido de la Ley de Urbanismo de Cataluña, señala lo siguiente:

El desarrollo urbanístico sostenible se define como la utilización racional del territorio y el medio ambiente y comporta combinar las necesidades de crecimiento con la preservación de los recursos naturales.

Visto lo anterior, estas políticas energéticas deberían contribuir al desarrollo sostenible, sustituir impedimentos e incentivos perversos por incentivos sanos que no obliguen al Estado a subsidiar las renovables continuamente, tal como exponía el economista y ex catedrático Rafael ZANONI ${ }^{10}$.

Así pues, para el Estado español — que no posee grandes reservas de petróleo o gas natural ni importantes recursos mineros, y que considera que la energía nuclear no es una alternativa viable - implantar políticas que favorezcan el uso de las energías renovables representa, bajo mi punto de vista, la única opción para conseguir un abastecimiento energético decente a un coste ambiental bajo.

El problema en el Estado español es el uso testimonial de algunas de las anteriores tecnologías energéticas, pues únicamente las energías eólica e hidráulica tienen una

\footnotetext{
9 “Declaración de la Conferencia de las Naciones Unidas sobre el Medio Humano”. Preámbulo.

${ }^{10}$ RAFAEL ZANONI, J., “¿Qué pueden hacer las políticas energéticas por la integración?”, Revista Mexicana de Política Exterior, octubre de 2005, México, p. 180.
} 
presencia significativa en España ${ }^{11}$, lo que supondría un problema para la seguridad del suministro energético cuando no hubiera sol o, en mayor medida, viento y precipitaciones, siempre y cuando se apostara básicamente por un modelo energético renovable. Aun así, esto podría matizarse con la integración energética de los países cercanos, más allá de lo que expone el artículo 122 del Tratado de Funcionamiento de la Unión Europea.

Por este motivo, hay que defender las energías renovables como parte del mix energético del Estado español y reducir progresivamente el uso de las energías convencionales y más contaminantes, hasta que la tecnología renovable alcance su madurez. Dicho de otro modo, ser realistas y convertir las renovables en el nexo entre la preocupación por el medio ambiente y el desarrollo económico del país, con el objetivo de contaminar mañana menos que hoy.

\section{ENERGÍAS RENOVABLES: ESTADO DE LA CUESTIÓN}

\section{El contexto internacional}

Según un estudio de la Frankfurt School para el Programa de las Naciones Unidas para el Medio Ambiente (PNUMA), gracias a la actividad de los países en desarrollo, 2014 fue un año de cambio positivo para las energías renovables ${ }^{12}$. Estas energías constituyen cerca de la mitad de la capacidad de energía neta agregada en todo el mundo ${ }^{13}$. Ciertamente, un número creciente de economías en desarrollo han optado decididamente por invertir en el sector de la energía verde o fomentar las inversiones. Así, China atrajo uno de cada tres dólares de las economías en crecimiento para la inversión en energías renovables (83,3 mil millones de dólares), más del doble de lo destinado por los Estados Unidos (38,3 mil

\footnotetext{
${ }^{11}$ ROLDÁN VILORIA, “Energías...” cit, p. 8.

${ }^{12}$ Frankfurt School. (2015). FS-UNEP Collaborating Centre. Global Trends in Renewable Energy Investment 2015. En el noveno reporte anual PNUMA “Tendencias Globales en la Inversión de Energías Renovables”, p. 4. Recuperado de http://www.fs-unep-centre.org.

${ }^{13}$ Esta frase la pronunció Achim Steiner, subsecretario general de la ONU y director ejecutivo del PNUMA, en Fráncfort el 31 de marzo de 2015 durante el noveno reporte anual del PNUMA. Debe tenerse en cuenta el gran crecimiento de la potencia mundial instalada en 2014, que, sin contar con las grandes centrales hidroeléctricas con sus $1.000 \mathrm{GW}$, era de $660 \mathrm{GW}$. La capacidad eléctrica en 2013 era de $318 \mathrm{GW}$ de eólica, $139 \mathrm{GW}$ de fotovoltaica, $88 \mathrm{GW}$ de biomasa, $12 \mathrm{GW}$ de geotérmica y 3,4 GW de solar termoeléctrica.
} 
millones de dólares). En palabras de Xavier Labandeira, catedrático de Economía de la Universidad de Vigo:

China se está dando cuenta que no se puede contraponer el desarrollo económico al medio ambiente, porque la polución, la escasez de agua o que esté contaminada, puede suponer un coste superior si se tienen en cuenta, por ejemplo, por el impacto sobre las enfermedades ${ }^{14}$.

Esta cita se ve reforzada por los datos que aporta la organización sin ánimo de lucro Berkeley Earth, según los cuales 1,6 millones de personas mueren cada año por la contaminación del aire en China ${ }^{15}$. Estos datos nos muestran hasta qué punto es perjudicial la contaminación atmosférica y puede explicar por qué China se ha hecho con un tercio de la inversión mundial en energías renovables, puesto que invertirá alrededor de 211.000 millones de euros para combatir la contaminación que afectará a gran parte del país en los próximos tres años. El 36,7\% de la inversión se destinará a la industria de "limpieza del aire", y otro $28,2 \%$ al impulso de las energías renovables ${ }^{16}$.

Cabe destacar también la inversión contabilizada en el continente asiático, con India (7,4 mil millones de dólares) e Indonesia (1,8 mil millones de dólares) a la cabeza. Según la web de energía renovable Bloomberg New Energy Finance (BNEF), la gran inversión que recibe la India puede atribuirse a la llegada al poder del partido BJP el pasado mayo, firme defensor de la energía limpia ${ }^{17}$. También Turquía (1,8 mil millones de dólares) ha realizado una inversión destacada.

En América Latina, Brasil es el país con una mayor inversión en energías renovables (7,4 mil millones de dólares) gracias a los mecanismos de apoyo —el Programa Proinfra y el sistema de licitación por tecnología específica—, seguido de México (2,1 mil millones de

\footnotetext{
${ }^{14}$ MEDIA VILLA, D., "SOS: el mundo se derrite", revista Muy Interesante, Extra medio ambiente. Cómo salvar la tierra, G y J España Ediciones, S. L., Madrid, mayo de 2015, p. 15.

${ }^{15}$ Berkeley Earth. (2015, agosto). Air Pollution Overview. Recuperado de http://berkeleyearth.org/airpollution-overview/.

${ }^{16}$ Fundación Vida Sostenible. (2014, marzo). Contaminación atmosférica en China. Recuperado de http:/www.vidasostenible.org/informes/contaminacion-atmosferica-en-china/.

${ }^{17}$ ICEX. España Exportación e Inversiones, India: la inversión en energía limpia superará los 8.820 millones de euros en 2015 (2015, marzo). Recuperado de http://www.icex.es/icex/es/Navegacion-zonacontacto/revista-el-exportador/noticias/NEW2015368909.html.
} 
dólares) ${ }^{18}$ como consecuencia de la reforma energética que abrió a las empresas privadas la posibilidad de generar electricidad. Chile (1,4 mil millones de dólares) es otro de los países del continente latinoamericano que más está progresando gracias a la Ley de Fomento de las Energías Renovables No Convencionales, que establece que para el año 2025 el 20\% de la electricidad ofertada a la red eléctrica sea de origen renovable. Hay otros países con una inversión que, aunque menor, supera los 500 millones de dólares (Costa Rica, Panamá y Uruguay $)^{19}$. Costa Rica ha puesto en marcha dos mecanismos que están facilitando la penetración de las energías renovables en el país: un sistema específico de subastas exclusivamente para fuentes renovables y una serie de exenciones de los impuestos de importación, IVA e impuestos sobre la renta para los equipos utilizados por la industria renovable ${ }^{20}$.

También son relevantes las inversiones en África: Kenia (1,3 mil millones de dólares) y especialmente Sudáfrica (5,5 mil millones de dólares), desde donde se pretende desplegar un corredor de energía limpia hasta Egipto, infraestructura de suma importancia ya que, según la Agencia Internacional de las Energías Renovables (IRENA), África tiene la tasa más baja de electrificación rural del mundo ${ }^{21}$.

En septiembre de 2014, China, EE. UU., Alemania y Japón fueron los países mejor valorados para invertir en fuentes de energía renovable según Ernst \& Young, mientras que España ocupaba la posición número $22^{22}$. Los 10 países que recibieron más inversiones en

\footnotetext{
${ }^{18}$ México, con $782 \mathrm{MW}$, estableció un nuevo récord de capacidad en el sector eólico, que atrajo cerca del $86 \%$ de la inversión de energías renovables del país. El mayor acuerdo fue para el Parque Eólico Sierra de Juárez, con 155 MW.

${ }^{19}$ MCCRONE, A (coord.) et ál., Global Trends in Renewable Energy Investment 2015, Frankfurt School UNEP Centre for Climate \& Sustainable Energy Finance, p. 20.

${ }^{20}$ RASO, Concha, “América Latina, el nuevo mercado de las renovables”, elEconomista.es, julio de 2015. Recuperado de http://www.eleconomista.es/energia/noticias/6906817/07/15/America-Latina-el-nuevomercado-de-las-renovables.html\#Kku8xEiOFf2xlh95.

${ }^{21}$ Wambi, Michael. (2015, enero). EuroXpress. El desarrollo de África pasa por las energías renovables. Recuperado de http://www.euroxpress.es/index.php/noticias/2015/1/22/el-desarrollo-de-africa-pasa-por-lasenergias-renovables/.

${ }^{22}$ Page, David. (2014, septiembre). España se hunde en el ranking mundial de mejores países para invertir en renovables. Madrid. Recuperado en junio de 2015, de http://www.expansion.com/2014/09/24/empresas/energia/1411571177.html.
} 
2014 fueron: China, EE. UU., Japón, Brasil, India, Sudáfrica, Chile, Kenia, México y Turquía.

El noveno informe anual del Programa de las Naciones Unidas para el Medio Ambiente, elaborado en marzo de 2015, indica que en 2014 se produjo un repunte del $17 \%$ de las inversiones en energía verde a nivel mundial, con 270,2 billones de dólares, sobre todo en energía eólica y solar ${ }^{23}$. Este aumento puede haberse frenado por el descenso de casi el 50\% en los precios del crudo entre junio de 2014 y marzo de 2015, que ha afectado al desarrollo de las energías renovables en algunos países en vías de desarrollo donde se quema sobre todo petróleo para obtener energía ${ }^{24}$. A este dato deben sumarse las incertidumbres políticas a las que deben hacer frente los sectores energéticos eólico y solar ${ }^{25}$.

\section{La Unión Europea}

La UE impulsó el sector de las energías renovables con diferentes libros blancos publicados por la Comisión Europea con la intención de proponer una acción comunitaria en el ámbito de las energías verdes para así iniciar un proceso de consultas a escala europea. Una vez que los postulados de los libros blancos son aceptados, los libros verdes invitan a las partes interesadas (organismos y particulares) a participar en un proceso de consulta y debate sobre las propuestas que se presentan. Este fue el caso de dos directivas (2001/77/CE y 2009/28/CE) que promovieron abiertamente las energías renovables con el objetivo de que cada país miembro pudiera elaborar sus propias normas de transposición. Todo empezó con el libro blanco "Una política energética para la Unión Europea", donde se reconocía que las energías renovables tendrían un papel fundamental para alcanzar los objetivos energéticos futuros ${ }^{26}$.

\footnotetext{
${ }^{23}$ MCCRONE, “Global...”" cit., p. 6.

${ }^{24}$ MCCRONE, “Global...” cit., p. 12.

${ }^{25}$ MCCRONE, “Global...” cit., p. 60.

26 “COM (95) 682 final, 13 December 1995. White Paper: An Energy Policy for the European Union”. Recuperado de http://aei.pitt.edu/1129/.
} 
$\mathrm{Al}$ año siguiente, la UE recomendó, con el libro verde "Energía por el futuro: fuentes de energía renovable"27, duplicar la cuota de renovables para los Estados miembros antes del 2010. Asimismo, con el fin de reducir las importaciones energéticas y aumentar la seguridad del suministro eléctrico, se redactó el libro blanco "Una estrategia y un plan de acción comunitarios" ${ }^{28}$. La Directiva 2001/77/CE del Parlamento Europeo y del Consejo, de 27 de septiembre de $2001^{29}$, fomentó la producción de electricidad generada a partir de fuentes de energía renovables en el mercado interior de la electricidad, ya que obligaba a los Estados miembros a aumentar el consumo de electricidad generada a partir de estas fuentes, que en ese momento eran las energías eólica, solar, geotérmica, oleaje, mareomotriz e hidráulica, biomasa, gases de vertedero, gases de plantas de depuración y biogás; esta directiva se quedó corta en sus aspiraciones y fue completada posteriormente.

Para hacer efectiva la promoción de la electricidad de origen renovable, se aprobó la Directiva Europea 2003/54/CE del Parlamento Europeo y del Consejo, de 26 de junio, relativa al mercado eléctrico interno, que obligaba, en su artículo tercero, a los suministradores de electricidad a aportar información sobre el origen y el impacto ambiental de su producto.

El libro verde "Estrategia europea para una energía sostenible, competitiva y segura" abrió un debate en el 2006 con el fin de reflexionar sobre las medidas necesarias que deberían adoptarse para mejorar los objetivos marcados en este ámbito para después del año $2010^{30}$.

Para completar la Directiva 2001/77/CE, la Comisión consideraba factible aumentar al 20\% la aportación de las fuentes de energía renovable en el consumo interior bruto para el

\footnotetext{
27 “COM (96) 576, 20 November 1996, Renewable energy: Green Paper”. Recuperado de http://eurlex.europa.eu/legal-content/EN/TXT/?uri=uriserv:127018.

28 “COM (97) 599, de 26 November1997, Energy for the future: Renewable sources of energy”. Recuperado de http://europa.eu/documents/comm/white_papers/pdf/com97_599_en.pdf.

${ }^{29}$ En la COM (2005) 627 final, se explicaba que el Estado español contaba entre los tres países (junto con Alemania y Dinamarca) que realizaron una transposición más beneficiosa en materia de energía eólica, con un sistema de tarifas reguladas muy eficaz.

30 “COM (2006) 105 final, 8 March 2006, A European Strategy for Sustainable, Competitive and Secure Energy”. Recuperado de http://eur-lex.europa.eu/legal-content/EN/TXT/?uri=CELEX:52006DC0105.
} 
$2020^{31}$, objetivo que se incorporó en el considerando 19 de la Directiva 2009/28/CE, de energías renovables. Esta directiva modificaba la clasificación de algunas fuentes renovables respecto a la Directiva 2011/77/CE, incluyendo la energía aerotérmica y agrupando oleaje y mareomotriz con energía oceánica ${ }^{32}$.

Con el Reglamento (CE) 663/2009 del Parlamento Europeo y del Consejo, de 13 de julio de 2009, se estableció un programa de ayuda financiera para proyectos en el ámbito energético, en el considerando 7 de dicho reglamento, se contemplaba el establecimiento de medidas que permitieran financiar proyectos coherentes con el Plan de Recuperación, como es el caso de los proyectos en el sector de la energía procedente de fuentes renovables.

Hoy en día, la Hoja de ruta de la energía para el año $2050^{33}$ indica que la proporción de las renovables en el sistema energético debe seguir creciendo después del año $2020^{34}$, ya que es la forma más segura de abaratar los precios de la energía, pues los costes de la electricidad tienen una importancia especial en la perspectiva de 2030 y se sugiere que los precios de esta continuarán aumentando ${ }^{35}$.

El recorrido anterior de las políticas adoptadas a nivel europeo en materia de energías renovables ha influido a favor de estas en las decisiones del legislador nacional de cada Estado miembro. Así, se puede valorar positivamente la promoción que hace la Unión Europea en favor de las energías renovables.

\footnotetext{
${ }^{31}$ Este objetivo ya se contempló en la COM (2006) 848. Así, el 9 de marzo de 2007 el Consejo Europeo de Primavera, con el apoyo del Parlamento Europeo y de los Estados miembros, acordó establecer un objetivo vinculante para el año 2020 en el sentido de que el 20\% de su consumo energético procediera de fuentes renovables.

${ }^{32}$ ABAD CASTELOS, M., Las energías renovables marinas y la riqueza potencial de los océanos: ¿un mar de dudas o un mar de oportunidades?, Bosch, 2013. El autor desglosa la energía oceánica en seis fuentes: las olas; la amplitud de las mareas; las corrientes de las mareas; las corrientes oceánicas; la energía térmica oceánica; y los gradientes de salinidad (p. 62).

${ }^{33}$ Parlamento Europeo. Energy roadmap 2050, a future with energy, Motion for a European Parliament resolution: on the Energy roadmap 2050, a future with energy (2012/2103(INI)), (2013, febrero).

${ }^{34}$ COM (2013) 169 final p. 9.

${ }^{35}$ BLASCO HEDO, E., "Libro verde sobre un marco para las políticas de clima y energía en 2030", Revista Aranzadi de Derecho Ambiental, núm. 25, mayo-agosto 2013, p. 364.
} 
No podría acabar este punto sin mencionar algunas ciudades europeas que apuestan por las energías renovables ${ }^{36}$ :

- Copenhague: utiliza sistemas de calefacción urbana limpia que cubren las necesidades del 98\% de la población. Un tercio de este calor se genera por la incineración de residuos y biomasa. Copenhague pretende ser 100\% libre de carbono neutral para el año 2025, pero ¿cómo pagarán estas políticas? Las pérdidas tributarias por el no consumo de carbón, petróleo y gas serán financiadas a través de una reestructuración de los impuestos ${ }^{37}$. - Estocolmo: tiene un sistema de calefacción urbana similar al de Copenhague. Los autobuses funcionan con energías renovables, fue Capital Verde Europea en 2010 y para 2050 se ha propuesto conseguir la independencia completa de los combustibles fósiles. La apuesta de esta ciudad es la electricidad como combustible del futuro ${ }^{38}$.

- Friburgo de Brisgovia: abogó por la energía solar frente a la atómica en 1986 después de la tragedia de Chernóbil. Hoy transforma los residuos urbanos en biogás, que usa para producir energía eléctrica y térmica.

\section{EL ESTADO ESPAÑOL}

\section{Estado de la cuestión}

La actividad de generación en régimen especial ${ }^{39}$, que se aplicaba a la producción de energía eléctrica en instalaciones de potencia no superior a $50 \mathrm{MW}$ que utilizaban como energía primaria las energías renovables, tenía reconocido un régimen jurídico y económico más beneficioso en comparación con el régimen ordinario, en el que se agrupaban las fuentes energéticas convencionales. Así fue desde la aprobación de la Ley 82/1980, de 30 de diciembre, sobre conservación de energía — motivada por la necesidad de hacer frente a

\footnotetext{
${ }^{36}$ CHAPARRO, L., "Ciudades ecológicas”, revista Muy Interesante, Extra medio ambiente. Cómo salvar la tierra, G y J España Ediciones, S. L., Madrid, mayo de 2015, pp. 32-45.

${ }^{37}$ Merino, Luis. (2012, enero). Dinamarca, a por todas en renovables. Recuperado en septiembre de 2015, de http:/www.energias-renovables.com/articulo/dinamarca-a-por-todas-en-renovables

${ }^{38}$ Equipo de redacción de Energías Renovables. (2015, marzo). Los buses de la línea 73 de Estocolmo se recargarán en seis minutos. Recuperado de http://www.energias-renovables.com/articulo/los-buses-de-lalinea-73-de-20150330
}

39 El artículo 27 de la extinta Ley 54/1997, de 27 de noviembre, del Sector Eléctrico, establece concretamente cuáles eran los beneficiarios de este régimen. 
la segunda crisis del petróleo-, hasta la entrada en vigor de la Ley 24/2013, de 26 de diciembre, del Sector Eléctrico.

En aquellos años, el Plan Energético Nacional de 1978-1987 se refería de manera testimonial a las energías renovables, sin prever objetivo alguno a alcanzar en el horizonte temporal para el que fue aprobado ${ }^{40}$. Así, en el caso de la energía eólica, en 1991 se contaba con una potencia instalada de 11,6 megavatios (MW). Cuando en 1999 se presenta el Plan de Fomento de las Energías Renovables, ya contaba con $900 \mathrm{MW}^{41}$.

Para alcanzar los objetivos del libro blanco de 1997 por el que se establece una estrategia y un plan de acción comunitarios ${ }^{42}$, en agosto de 2005 se aprobó el Plan de Energías Renovables (PER) 2005-2010, al que le seguiría la Estrategia Española de Cambio Climático y Energía Limpia. Horizonte 2007-2012-2020 ${ }^{43}$. Dicho documento estratégico sirvió de base para elaborar el Plan de Energías Renovables 2011-2020 con el objetivo de que a partir del año 2010 las energías renovables pudiesen competir con los combustibles fósiles ${ }^{44}$. Los datos de este plan atribuyeron a la electricidad renovable una producción bruta de electricidad en 2010 del $32,3 \%$ de la cobertura total de la demanda eléctrica nacional ${ }^{45}$.

El artículo 78 de la Ley 2/2011, de 4 de marzo, de Economía Sostenible, estableció posteriormente que las energías renovables tendrían una participación del 20\% sobre el

\footnotetext{
${ }^{40}$ QUINTANA LÓPEZ, T., "El régimen jurídico de la energía eólica. Referencia a Castilla y León”, Revista de estudios de la administración local, núm. 291, 2003, ISBN 1578-4568, p. 963.

${ }^{41}$ RICO, J., "Un futuro cien por cien renovable", revista Muy Interesante, Extra medio ambiente. Cómo salvar la tierra, G y J España Ediciones, S. L., Madrid, mayo de 2015, p. 54.

${ }^{42}$ MINISTERIO DE INDUSTRIA, ENERGÍA Y TURISMO, SECRETARÍA DE ESTADO DE ENERGÍA, "Informe sobre las medidas de actuación de ahorro y eficiencia energética en cumplimiento del artículo 7", p. 4.

${ }^{43}$ Aprobada por el Consejo de Ministros el 2 de noviembre de 2007.

${ }^{44}$ BLESA MARTÍNEZ, B., "Nuevas tecnologías que contribuyen a mitigar el cambio climático: las instalaciones sostenibles en el mar territorial”, Revista Aranzadi de Derecho Ambiental, núm. 18, p. 344.

${ }^{45}$ La energía eólica contribuyó con más de $43.700 \mathrm{GWh}$ (un 16\%); la solar fotovoltaica contó en 2010 con 3.787 MW de potencia instalada, que produjeron 6.279 GWh; el sector solar térmico contó en 2010 en España con 1.657 MW, que produjeron $2.128 \mathrm{GWh}$; y el sector solar termoeléctrico contó con $632 \mathrm{MW}$ de potencia instalada, que produjeron $691 \mathrm{GWh}$.
} 
consumo final bruto de energía para el $2020^{46}$. En 2013 este consumo final bruto fue del $16,6 \%$, superior al 15,9\% incluido en el PER 2011-2020 ${ }^{47}$.

A día de hoy, el Estado español cuenta con la Planificación Indicativa para el período 20152020 con el objetivo de financiar proyectos urbanos de eficiencia energética y de uso de las energías renovables que deben garantizar el cumplimiento de los objetivos previstos en el Plan Nacional de Acción de Eficiencia Energética 2014-2020, cuya implementación se apoya en el Fondo de Inversión en Diversificación y Ahorro de Energía ${ }^{48}$, dotado con 123 millones de euros.

Según Red Eléctrica, el conjunto de las renovables aportó en 2014 el 42,8\% de la producción eléctrica total, hidráulica incluida $(15,4 \%)$, lo que las sitúa en un primer puesto, seguidas de la nuclear $(21,9 \%)$, el gas $(18,9 \%)$, y el carbón $(16,4 \%)^{49}$. En 2014 , la Asociación Empresarial Eólica situaba en 22.986 MW la potencia eólica instalada.

\subsection{La contribución de las energías renovables en el Estado español}

En este apartado se exponen, analizan y explican los beneficios que nos aportan las energías renovables, beneficios que, como se muestra en la introducción, son examinados desde una óptica de sostenibilidad ambiental, social y económica.

- Ventajas asociadas a las energías renovables: son abundantes y de acceso gratuito, se hallan en el medio natural y se pueden obtener en lugares aislados ${ }^{50}$.

- Reducción del precio de la electricidad en el mercado eléctrico: la existencia de la generación a partir de fuentes renovables da como resultado la fijación de precios marginales más bajos en el mercado mayorista de energía, ${ }^{51,52}$ lo que no coincide con el

\footnotetext{
${ }^{46}$ Este objetivo se fijó en el 20,8\% sobre el consumo final bruto de energía después del Acuerdo Social y Económico de enero de 2011. Dato que se extrae de la tabla 5.4.1, p. 466, del PER 2011-2020.

${ }^{47}$ ASOCIACIÓN DE EMPRESAS DE ENERGÍAS RENOVABLES, Estudio del Impacto Macroeconómico de las Energías Renovables en España en 2013, p. 158.

${ }^{48}$ MINISTERIO DE INDUSTRIA, ENERGÍA Y TURISMO, SECRETARÍA DE ESTADO DE ENERGÍA, Informe... cit., p. 26.

${ }^{49}$ RICO, J., "Un futuro cien por cien renovable”, revista Muy Interesante, Extra medio ambiente. Cómo salvar la tierra, G y J España Ediciones, S. L., Madrid, mayo de 2015, p. 54.

${ }^{50}$ ROLDÁN VILORIA, “Energías renovables...” cit. p. 49.

${ }^{51}$ ASOCIACIÓN DE EMPRESAS DE ENERGÍAS RENOVABLES, Estudio del Impacto... cit., p. 21.
} 
continuado incremento de la factura de la luz, donde el usuario medio paga 400 euros anuales más que en $2005^{53}$, dinero que va a empresas eléctricas vinculadas en algún momento con ex miembros del ejecutivo del Estado español.

- Generación descentralizada de energía: se aumenta la eficiencia del sistema al disminuir las pérdidas en el trasporte de electricidad ${ }^{54}$, ya que el consumidor está cerca del punto de producción y se consigue que la generación no dependa tanto de las grandes centrales eléctricas ${ }^{55}$. Es el fundamento del autoconsumo.

- Desarrollo técnico y científico: hay empresas que planifican a largo plazo en $\mathrm{I}+\mathrm{D}$ teniendo en cuenta las características de las energías renovables para evitar las modernizaciones costosas en estadios posteriores ${ }^{56}$. Algunas de ellas están en nuestro país ${ }^{57}$. Este desarrollo tiene un impacto en el PIB español y a su vez crea empleo. Esta planificación está reduciendo los costes de las tecnologías limpias.

- Contribución al cumplimiento de los objetivos de la UE: en el período 2005-2013, las energías renovables han evitado la emisión a la atmósfera de más de 256,8 millones de toneladas de $\mathrm{CO}_{2}{ }^{58}$. En 2014, España alcanzó el 17,1\% de grado de penetración de renovables, por encima del $12,1 \%{ }^{59}$ previsto para $2020^{60}$. La reducción de la dependencia

\footnotetext{
${ }^{52}$ Energía oscura. (2015, mayo). Mercado diario. Recuperado de http://www.energiaoscura.es/como-se-fijanlos-precios/mercado-diario/

${ }^{53}$ FACUA-Consumidores en Acción. (2015, agosto). Tarifazo Eléctrico. Un 76\% más de luz en 10 años. Recuperado de https://www.facua.org/es/noticia.php?Id=9594

${ }^{54}$ Observa el mercado eléctrico. (2015, mayo). Falacias del mercado eléctrico. Recuperado de http://www.observaelmercadoelectrico.net/Entiende/index45.html\#go_index

${ }^{55}$ Endesa. (2015, mayo). Generación distribuida. Recuperado de http://www.endesaeduca.com/Endesa_educa/recursos-interactivos/smart-city/generacion-distribuida

56 International Energy Agency (OCDE/IEA). Energy Technology Perspectives 2014 - Executive Summary Spanish version, mayo de 2015, París, p. 8.

${ }^{57}$ Alstom desarrolla, en su sede de Barcelona, I+D en energía eólica. Además, en fabricación de generadores hidroeléctricos es referencia mundial, motivo por el que recibió el premio Euskal Makila. Otra empresa importante es Adwen, fusión de Gamesa y Areva en marzo de 2015. Adwen desarrolla actividades de I+D de turbinas offshore. La misma Gamesa batió, en septiembre de 2014, el récord de producción mensual en España con 3.136 megavatios hora (MWh); una turbina actual equivale a casi veinte de hace treinta años. Vortex ha abierto en 2015 una filial en Boston para promocionar un aerogenerador sin palas.

${ }^{58}$ ASOCIACIÓN DE EMPRESAS DE ENERGÍAS RENOVABLES, Estudio del Impacto... cit., pp. 108109.

${ }^{59}$ Dato que se halla en la Tabla 5.4.1. Objetivos globales del Plan de Energías Renovables (PER) 2011-2020 y grado de cumplimiento de los objetivos obligatorios e indicativos de la Directiva 2009/28/CE, p. 466 del PER 2011-2020.
} 
energética evita la importación de combustibles fósiles, lo que, a su vez, ayuda a cumplir los compromisos internacionales de emisión de gases invernadero firmados por el Estado español. Finalmente, cabe citar a ALENZA GARCÍA, quien ya detectó este aspecto en 2004:

[...] resulta esencial cambiar el modelo energético imperante y sustituirlo con bajas emisiones de carbono, lo cual tendría, además, otras ventajas adicionales como reducir la dependencia energética del exterior y mejorar la competitividad europea ${ }^{61}$.

- Proyectos para abastecernos de forma autosuficiente: El Hierro será la primera isla autosuficiente con combinación hidráulico-eólica. En junio de 2014 se pusieron en marcha cinco aerogeneradores con una potencia de 2,3 MW cada uno conectados a un sistema que cuenta con un depósito de agua superior y otro inferior unidos por tuberías. El funcionamiento es simple y se prevé eficaz; el excedente energético eólico de los aerogeneradores va a una central de bombeo que se usa para enviar agua del depósito inferior al superior, utilizando así la energía potencial del agua a modo de batería ${ }^{62}$.

- Aumento de la biodiversidad y productividad: la colocación de infraestructuras en el fondo del mar o en la columna de agua ${ }^{63}$, de las energías renovables marinas puede aumentar la colonización local, si bien también los organismos marítimos no autóctonos, y puede dificultar prácticas dañinas como la pesca de arrastre ${ }^{64}$.

- Beneficios sociales: la disminución de la contaminación, la menor dependencia energética exterior y la contención del coste energético favorecen un mayor acceso energético limpio a las clases sociales más desfavorecidas, lo que genera una mejor calidad de vida y un desarrollo humano más beneficioso. Además, la economía de la zona se puede

\footnotetext{
${ }^{60}$ CONSEJO DE MINISTROS DE ESPAÑA, Programa Nacional de Reformas del Reino de España 2015, p. 42.

${ }^{61}$ PEREIRA BLANCO, M., "Las energías renovables: ¿es posible hablar de un derecho energético ambiental? Elementos para una discusión”, Jurídicas CUC, 2015, p. 243.

${ }^{62}$ CHAPARRO, L., “Ciudades ecológicas”, revista Muy Interesante, Extra medio ambiente. Cómo salvar la tierra, G y J España Ediciones, S. L., Madrid, mayo de 2015, p. 43.

${ }^{63}$ Entendiéndose esta como una la masa acuosa de agua salina poblada de organismos pelágicos.

64 ABAD CASTELOS, Las energías renovables... cit., pp. 89-90.
} 
ver afectada positivamente con la creación de puestos de trabajo, alquileres y pagos por el uso de la tierra ${ }^{65}$.

- Limitar el uso de la geoingeniería: se desconocen el efecto y las consecuencias del uso de esta tecnología a largo plazo. El informe para 2013 del Grupo Intergubernamental de Expertos sobre el Cambio Climático admite que la geoingeniería será inevitable si la temperatura media global se eleva por encima de dos grados Celsius ${ }^{66}$, motivo por el que es tan importante el uso de las energías renovables si se quiere evitar recurrir a esta tecnología, que prevé dos estrategias para mitigar el calentamiento global:

a) Solar Radiation Management (SRM): consiste en reflejar una pequeña parte de la energía solar a través de nubes reflectantes sobre los océanos, reflectores espaciales entre la Tierra y el Sol, y aerosoles en la estratosfera para crear diminutos espejos.

b) Carbon Dioxide Removal (CDR): consiste en retirar el $\mathrm{CO}_{2}$ sobrante con planes de reforestación masiva, bioenergía para capturar el $\mathrm{CO}_{2}$, captura directa con dispositivos, fertilización de los océanos para incrementar la producción primaria encargada de absorber $\mathrm{CO}_{2}$ y disolución mejorada de minerales que reaccionen con el $\mathrm{CO}_{2}$ y lo capturen.

\section{Retos de las energías renovables en el Estado español}

Pueden ser los aspectos que impiden el correcto desarrollo de las fuentes de energía renovable. Aquí se pone el acento en los problemas del sistema actual y se pretende aportar alguna solución.

- Influencia de los poderosos: el Gobierno es rehén del déficit tarifario y puede ser un objetivo apetecible para las grandes eléctricas. Dicho esto, quizás no sea una buena práctica la salida de miembros del ejecutivo español para ocupar cargos en las grandes eléctricas

65 LÓPEZ SAKO, J., Regulación y autorización de los parques eólicos, Aranzadi, Cizur Menor, 2008, p. 63. ${ }^{66}$ DAGANDO, J.M., "Cómo hackear el clima", revista Muy Interesante, Extra medio ambiente. Cómo salvar la tierra, G y J España Ediciones, S. L., Madrid, mayo de 2015, p. 96. 
(Revolving doors) ${ }^{67}$. A modo de ejemplo: en el año 2011 fue fichado por Endesa el expresidente José María Aznar como asesor externo; Felipe González ejerció desde 2010 como consejero independiente de Gas Natural; Elena Salgado fue incorporada como consejera por una filial de Endesa en Chile; y Pedro Solbes trabajó como consejero para la italiana ENEL ${ }^{68}$. Para justificar tal despropósito, las eléctricas argumentan que se trata de personas con experiencia y criterio, y no solo lo justifican estas, sino también el Sr. Miquel Iceta, presidenciable por el PSC a las elecciones autonómicas de Cataluña, que, durante una entrevista en septiembre de 2015 en 8tv, afirmó que, si esperamos políticos que no se eternicen en los cargos, se debe permitir el paso a la empresa privada después del tiempo que marca el artículo 8 de la Ley 5/2006, de 10 de abril, de regulación de los conflictos de intereses de los miembros del Gobierno y de los Altos Cargos de la Administración General del Estado. Pero lo que realmente busca el lobby eléctrico son los contactos de los exdirigentes para así poder influir en las nuevas regulaciones, no su criterio y experiencia. En definitiva, creo que se debe prohibir el paso del ejecutivo a los lobbies. Por otro lado, el discurso de algunos políticos en defensa de la regeneración ciudadana de sus ex cargos públicos para, en algún caso, ir a los grandes ejecutivos privados me parece inmoral.

- La regulación de la autogeneración de energía eléctrica: se prevé que este mes de septiembre de 2015 se apruebe el Real Decreto sobre autoconsumo ${ }^{69}$. Pero, a día de hoy, solo tenemos una propuesta de Real Decreto que modifica la antigua propuesta de Real Decreto de autoconsumo del 18 de julio de 2013. El artículo 16 de esta antigua propuesta introducía un peaje de respaldo al sistema eléctrico que no agradaba ni a oposición, ni a ciudadanía ni tampoco a gobiernos del mismo partido político de comunidades autónomas que, como la murciana, tenían previsto modificar su normativa de energías renovables y ahorro y eficiencia energética para eliminar los peajes y potenciar el autoconsumo ${ }^{70}$.

\footnotetext{
${ }^{67}$ La puerta giratoria es una de las formas más importantes en que los grupos de presión pueden influir en la agenda política en Madrid, para que se regule de forma efectiva en pro de sus intereses.

${ }^{68}$ VILLORIA, M. (dir.), REVUELTA, A. (coord.) et ál., "Evaluación del lobby en España: Análisis y propuestas", Transparencia Internacional, Madrid, 2015, p. 82.

${ }^{69}$ Esta propuesta de Real Decreto se encuentra recogida en la medida 41 del anexo IV, "Medidas adicionales para apoyar el crecimiento y el empleo", del Programa Nacional de Reformas del Reino de España 2015, aprobado el 24 de abril de 2015 por el Consejo de Ministros de España y remitido a Bruselas.

${ }^{70}$ ROCA, Ramón, "Los murcianos, los primeros autoconsumidores españoles con balance neto que no pagarán el 'impuesto al sol”, El periódico de la energia.com, mayo de 2015. Recuperado de
} 
Pero en el nuevo borrador de proyecto de Real Decreto — por el que se establece la regulación de las condiciones administrativas, técnicas y económicas de las modalidades de suministro de energía eléctrica con autoconsumo y de producción con autoconsumoalgunos preceptos han cambiado: desaparece el peaje de respaldo que encontrábamos en el artículo 16 del anterior borrador y aparece un pago a realizar para respaldar el sistema eléctrico (artículo 21.1.) ${ }^{71}$. Además, el autoconsumo que realicen las viviendas ya no será incompatible con tener contratado el Precio Voluntario al Pequeño Consumidor o el bono social. Las instalaciones domésticas que no envíen la energía a la red no deberán pagar los estudios de acceso y conexión a la red $^{72}$, y aquel autoconsumidor que genere la electricidad que consume y que no esté conectado a la red solo pagará el coste de la inversión de su instalación.

El problema radica en la dificultad de ser un autoconsumidor no conectado a la red, pues hay una limitación a la opción técnica de aislarse de la red de distribución si esta es técnicamente accesible (según el artículo 3 , apartado $\mathrm{k})^{73}$, lo que en la práctica supondría tener que estar conectado a la red y pagar los respaldos.

En cambio, aquellos autoconsumidores conectados a la red y que, en consecuencia, se benefician del respaldo que les proporciona el conjunto del sistema, cuando produzcan un excedente de energía distribuirán esta energía excedente a la red sin contraprestación alguna, a diferencia de lo que sucede en Alemania, Croacia o Dinamarca, países en los cuales se paga una prima por la electricidad vertida a la red de esta forma.

¿Por qué, pues, el Gobierno insiste - en la mayoría de los supuestos- en que los autoconsumidores deberán pagar los peajes de transporte y distribución y los costes de los servicios? La respuesta es clara: porque, en caso contrario, el resto de consumidores debería

\footnotetext{
http:/elperiodicodelaenergia.com/los-murcianos-los-primeros-autoconsumidores-espanoles-con-balance-netoque-no-pagaran-el-impuesto-al-sol/.

71 “El Ministro de Industria, Energía y Turismo determinará la cuantía correspondiente al cargo por otros servicios del sistema, definido como el pago a realizar por la función de respaldo que el conjunto del sistema eléctrico realiza para posibilitar la aplicación del autoconsumo, conforme establece el artículo 9.3 de la ley 24/2013 de 26 de diciembre".

${ }^{72}$ Siguiendo la lógica del artículo 4.3 del Real Decreto 1699/2011, de 18 de noviembre, por el que se regula la conexión a red de instalaciones de producción de energía eléctrica de pequeña potencia.

${ }^{73}$ Salas, Pep. (2015, junio). Nou esborrany de Reial Decret sobre Autoconsum: un nou pas enrere. Recuperado de http:/www.smartgrid.cat/index.php/smartgrids/126-nou-esborrany-de-reial-decret-sobreautoconsum-pitjor-impossible.
} 
hacer frente a esos costes. De igual forma, la Fundación para el Análisis y los Estudios Sociales (FAES) cree que si los consumidores dejaran de pagar por el autoconsumo, los costes fijos del sistema no desaparecerían y, por lo tanto, se tendrían que recaudar del resto de los consumidores ${ }^{74}$.

No pasa así en otros países europeos, que ven el autoconsumo como una medida de eficiencia energética que en sí no genera costes adicionales al sistema sino todo lo contrario. Por ejemplo, en Italia las instalaciones inferiores a $20 \mathrm{~kW}$ no pagan ningún tipo de cargo o impuesto; en Portugal están exentas hasta que el autoconsumo alcance el 3\% de la potencia total instalada en el país; y en Alemania pagan cargos, pero reciben una prima mayor que estos.

Eso sí, cuando la instalación de generación o de consumo esté conectada total o parcialmente al sistema eléctrico, el usuario del autoconsumo, es decir, aquel que produzca energía y la consuma, tendrá la obligación de contribuir a los costes y servicios del sistema por la energía que él ha producido y consumido, pero no al peaje de acceso a redes por la energía producida y consumida por el usuario, teniendo en cuenta que no ha hecho uso de la red.

Otro punto interesante es el uso de baterías que se cargan con la propia energía autogenerada, pues se penalizará con impuestos. En cambio, el Gobierno alemán devuelve hasta el 30\% de impuestos por la adquisición de una batería para autoconsumo y préstamos a tipo de interés bajo para su compra.

Finalmente, la generación eléctrica en las islas es más cara que en la península ibérica; por lo tanto, se establece un incentivo al autoconsumo consistente en una reducción del pago de los costes regulados del sistema ${ }^{75}$.

En resumen, estos cambios favorecen el autoconsumo de acuerdo con los postulados de la Comisión Europea, que opina que los consumidores deben tener la libertad de generar y

\footnotetext{
${ }^{74}$ Navarro, Conrado y López, Juan. Papeles FAES número 178, febrero de 2015, El “consumidor generador”: implicaciones del autoconsumo en el sistema eléctrico, p. 9. Recuperado de http://www.fundacionfaes.org/file_upload/publication/pdf/20150216113345el_consumidor_generador__implicaciones_del_autoconsumo_en_el_sistema_electrico.pdf.

${ }^{75}$ NOCEDA, Miguel Ángel, "Pros y contras del autoconsumo eléctrico”, El País, Madrid, junio de 2015. Recuperado de http://economia.elpais.com/economia/2015/06/24/actualidad/1435163869_581409.html
} 
consumir su propia energía en condiciones justas con el fin de ahorrar dinero, ayudar al medio ambiente y garantizar la seguridad del suministro ${ }^{76}$. Aunque, para muchos, son aún insuficientes y no premian la eficiencia energética que aporta el autoconsumo como generación distribuida.

- Cambios en las retribuciones, primas y tarifas: la aplicación repetida de medidas de carácter retroactivo, por ejemplo, en el Real Decreto-Ley 2/2013, de 1 de febrero, de medidas urgentes en el sistema eléctrico y en el sector financiero ${ }^{77}$, y en el Real Decreto 413/2014, de 6 de junio, por el que se regula la actividad de producción de energía eléctrica a partir de fuentes de energía renovables, cogeneración y residuos ${ }^{78}$, ha contribuido a situar el sector eléctrico dentro de la inseguridad jurídica como consecuencia de redefinir la retribución, las tarifas y las primas de las energías renovables.

Así, los pequeños empresarios que invirtieron en renovables se enfrentan al impago de los préstamos bancarios que pidieron ya que las reglas del juego relativas a las retribuciones, tarifas y primas han cambiado y se han ido recortando las ayudas ${ }^{79}$. Véase por ejemplo, el efecto de la variación de regímenes en la retribución de las instalaciones fotovoltaicas, limitando primero el tiempo que los titulares de estas instalaciones estás tenían derecho a recibir una prima, para finalmente transmutar ese derecho en otro que se define como el derecho a obtener una rentabilidad razonable por parte de $\operatorname{estos}^{80}$. Algunas de las consecuencias son: la inestabilidad regulatoria, el retroceso, el fracaso de las políticas

\footnotetext{
${ }^{76}$ Comisión Europea. (2015, julio). Press release. Transforming Europe's energy system, Commission's energy summer package leads the way Brussels, 15 July 2015. Recuperado de http://europa.eu/rapid/pressrelease_IP-15-5358_en.htm

${ }^{77}$ J\&A Garrigues, S.L.P. (2013, febrero). Aprobado nuevo Real Decreto-Ley para contener el déficit tarifario. Recuperado en mayo de 2015 de http://www.garrigues.com/es/Publicaciones/Alertas/Paginas/Aprobado-unnuevo-Real-Decreto-Ley-para-contener-el-deficit-tarifario.aspx

${ }^{78}$ Efinétika blog. (2014, junio). RD 413/2014: Viajando atrás en el tiempo, la magia de la retroactividad. Recuperado en mayo de 2015 de https://efinetika.wordpress.com/2014/06/13/rd-4132014-viajando-atras-enel-tiempo-la-magia-de-la-retroactividad/.

${ }^{79}$ Rodrigo, Carlos. (2014, junio). Cinco claves para entender la problemática sobre las primas a las renovables. Recuperado en mayo de 2015, de http://blogs.hoy.es/eneltintero/2014/06/10/cinco-claves-paraentender-la-problematica-sobre-las-primas-a-las-renovables/.

${ }^{80}$ PONT CASTEJÓN, I. y NIETO MORENO, J., “Actuación ambiental del Estado: planificación hidrológica, política energética y calidad del aire", p. 261, Observatorio de Políticas Ambientales 2014, ThomsonAranzadi, Pamplona, 2014.
} 
llevadas a cabo en materia de energía renovable a nivel nacional y el empeoramiento que sufre el régimen retributivo de esta tecnología ${ }^{81}$.

Todo ello ha provocado un malestar generalizado en el sector que ha generado un sinfín de quejas como las del consejero delegado de la Asociación Europea de Energía Eólica (EWEA), Thomas Becker, durante la Feria de Barcelona de 10 de marzo de 2014: "El Gobierno español está dando el peor ejemplo posible a otros países", afirmó; y después añadió: "Es difícil entender cómo España puede poner en peligro a su industria eólica, que es líder mundial". José López-Tafall, presidente de la Asociación Empresarial Eólica (AEE), en la misma Feria también mostró una opinión similar: "Mientras que en Europa nos premian, en España el sector eólico es el más perjudicado por la nueva regulación. [...] España sacrifica injustamente una de sus industrias más innovadoras, que crea más empleo, que tiene más futuro en todo el mundo y que es, de hecho, imagen de la marca España”. En definitiva, el marco regulador del sector eléctrico es cambiante e inestable con las energías renovables $^{82}$, y si estas son tan importantes para no contaminar más el planeta, como parece reflejar la orientación del derecho europeo, debe cuestionarse si normas que desincentivan la inversión en la producción de energía a partir de fuentes renovables son correctas ${ }^{83}$.

El problema es el cambio de retribuciones, tarifas y primas, y la solución debe ser dar seguridad a los pequeños empresarios que quieren invertir en el Estado español.

- Disparidad y poco acceso a los datos de algunas asociaciones de energías renovables: No ayuda a la transparencia y al estudio que algunos datos sobre energías renovables, como los proporcionados por la Asociación de Empresas de Energías Renovables (AEER)-APPA, no coincidan con los de la Comisión Nacional de los Mercados y la Competencia (CNMC). Al buscar dónde se hallan esas diferencias, la asociación AEER no facilita el acceso a los datos que se contemplan en sus estudios y notas de prensa,

\footnotetext{
${ }^{81}$ RUIZ OLMO, I., "Las renovables ante los recientes cambios normativos: el episodio jurisprudencial del RD 1565/2010, que modifica la tarifa retributiva de la energía fotovoltaica", Actualidad jurídica ambiental, Marzo 2014, p. 25.

${ }^{82}$ Estanislao Arana García, catedrático de Derecho Administrativo en la Universidad de Granada, durante el Congreso Internacional de Energías Renovables y Cambio Climático, 23, 24 y 25 de octubre de 2013 en Pamplona (Navarra).

${ }^{83}$ MORA RUIZ, M., "La ordenación jurídico-administrativa de las energías renovables como pieza clave en la lucha contra el cambio climático: ¿un sector en crisis?”, Actualidad jurídica ambiental, febrero de 2014, p. 21.
} 
alegando que dicha asociación solo vela por el interés de sus asociados. Por su parte, el órgano público que maneja los datos oficiales respondió favorablemente a la demanda informativa sobre el cálculo de cifras en relación con las energías renovables en el Estado español.

Las discrepancias vienen de una nota de prensa de la APPA que cifraba en 7.500 millones de euros lo que las tecnologías renovables deberían haber recibido de acuerdo con las previsiones del Ministerio de Industria. Finalmente, las tecnologías renovables recibieron 5.239 millones $^{84}$, y se concluía en dicha nota de prensa: "Los datos indicados demuestran que las energías renovables han sido las grandes damnificadas por la reforma eléctrica realizada por el Gobierno" $\$ 55$.

El problema surge cuando buscamos la cifra que les corresponde a las tecnologías renovables en la liquidación número 13 del año 2014 realizada por la CNMC, que es de 6.683 millones de euros ${ }^{86}$, no de 7.500 millones.

En definitiva, hace falta más complicidad, colaboración y capacidad de comunicación por parte de las entidades privadas, que seguro que tienen sus razones y su verdad. Sin embargo, desgraciadamente, en este estudio su datos no se han podido analizar y comparar con los datos oficiales.

- Los principios generales del sistema de retribución de la Ley 24/2013: el principio de "empresa eficiente y bien gestionada" como fundamento del régimen retributivo de las renovables es un concepto jurídico indeterminado que exige concreción ${ }^{87}$. Esta retribución

\footnotetext{
${ }^{84}$ COMISIÓN NACIONAL DE LOS MERCADOS Y LA COMPETENCIA, "Informe sobre los resultados de la liquidación provisional 13 de 2014 de la retribución de las instalaciones de producción de energías renovables, cogeneración y residuos", p. 13. Para encontrar esta cifra se debe ir a la p. 7, tabla 2. Se debe calcular la suma de las energías renovables menos la suma de la cogeneración, los residuos y el tratamiento de residuos. La cifra resultante es 5.238,551, que aproximadamente nos da el valor de 5.239 millones de euros.

${ }^{85}$ Asociación de Empresas de Energías Renovables-APPA. Nota de prensa de 8 de abril de 2015, Madrid. Recuperado de http://www.appa.es/descargas/20150408_APPA_RECORTES_EERR_2014_VF_8.pdf.

${ }^{86}$ Esta cifra también se encuentra en la CNMC. "Informe sobre la propuesta de orden por la que se determinan los peajes de acceso de energía eléctrica para 2015”. IPN/DE/0014/14 de 11 de diciembre de 2014 , p. 23.

${ }^{87}$ MENDOZA LOSANA, A., “Adiós al régimen especial de retribución de instalaciones de producción a partir de tecnologías renovables, cogeneración y residuos en la nueva ley 24/2013, del sector eléctrico", Noticias Breves, enero de 2014, Gómez - Acebo \& Pombo, p. 2.
} 
se dará sobre la base de los ingresos por la venta de la energía a precio de mercado, los costes de explotación y la inversión inicial ${ }^{88}$.

- Prioridad de las energías renovables: el artículo 6.2 del Real Decreto 413/20140 elimina en gran parte el derecho prioritario de verter la energía a la red eléctrica de las energías renovables respecto a las energías convencionales. Por este motivo, el eurodiputado Ernest Urtasun ha promovido que la Comisión Europea investigue a España por este tema ${ }^{89,90}$. En mi opinión, este decreto podría vulnerar el artículo 16.2 letra c) de la Directiva 2009/28/CE, ya que esta prioridad desaparece excepto en casos muy concretos, por lo que cabría recuperar el redactado de la Directiva para promover las energías renovables.

- Déficit tarifario: según el Gobierno, la reforma eléctrica de 2012, 2013 y 2014 ha eliminado el problema del déficit de tarifa ${ }^{91}$ y supone un ahorro estimado de 1.700 millones de euros ${ }^{92}$. Pero no hay que olvidar que el reconocimiento del déficit de tarifa fue un éxito notable del lobby de la industria eléctrica ${ }^{93}$.

- Los problemas asociados a cada tecnología: hay que tener en cuenta los efectos negativos que tienen las actividades energético-renovables en todas sus fases (instalación, vida y desmantelamiento). Los inconvenientes de los aerogeneradores suelen ser el ruido y el impacto visual y sobre las aves; respecto a las tecnologías marinas, destaca la alteración de los hábitats de los fondos marinos ${ }^{94}$; las grandes instalaciones de energía solar requieren un extensa superficie de suelo, y la hidroeléctrica, la inundación de grandes superficies; etc.

\footnotetext{
${ }^{88}$ ALONSO TIMÓN, A., Sectores regulados: Sector energético, sector del transporte y sector de las telecomunicaciones, Dickinson SL, Madrid, 2014, p. 91.

${ }^{89}$ Clúster de la energía. (2015, febrero). La Comisión Europea investiga a España por saltarse a la torera la prioridad de despacho de las renovables. Recuperado de http://www.energiaextremadura.org/sala-deprensa/semana-de-las-energias-renovables-del-2-al-4-de-marzo/.

${ }^{90}$ Pérez Rodríguez, Daniel. (2014, noviembre). El derecho a la prioridad de despacho peligra en España. El Blog de la Energía Sostenible. Recuperado de http://www.blogenergiasostenible.com/derecho-prioridaddespacho-peligra-espana/.

${ }^{91}$ CONSEJO DE MINISTROS DE ESPAÑA, Programa Nacional de Reformas del Reino de España 2015, Madrid, mayo de 2015, p. 10-11.

${ }^{92}$ CONSEJO DE MINISTROS DE ESPAÑA, “Programa nacional..."cit., p. 180.

${ }^{93}$ MARTÍN GALLEGO, M., "La electricidad, clave de la política energética”, Temas para el debate, 236, julio de 2014, p. 21-24.

${ }^{94}$ ABAD CASTELOS, Las energías renovables... cit., p. 102.
} 
Además, hay que contar con que algunas tecnologías no tienen una continuidad en la generación de energía eléctrica debido a que no siempre hace sol o viento, por ejemplo. Para solucionar el problema de suministro que pueden presentar las renovables al no poseer una continuidad segura en la generación de energía eléctrica, se debería promover un mix energético entre energías renovables y convencionales, tal como expongo en la introducción.

- La incertidumbre científica y tecnológica: si no se reduce el aumento de temperatura que los modelos computacionales prevén para nuestro planeta, se deberá aplicar la geoingeniería y arriesgarnos a largo plazo a sufrir unos efectos desconocidos sobre el clima planetario. Por lo tanto, debemos aumentar el uso de las energías renovables ya que contribuyen a reducir la concentración de gases de efecto invernadero que impulsa el cambio climático. Pero ¿son acaso suficientes las energías renovables para evitar la combustión de combustibles fósiles con el fin de reducir la contaminación atmosférica? ¿Sabemos realmente lo que comporta la disminución de estas partículas en la estratosfera? ${ }^{95}$ Puede haber un cambio de paradigma en la forma de responder a estas dos preguntas:

1. Según datos y modelos computacionales de la NASA ${ }^{96}$, la polución atmosférica asiática proveniente de países como China y la India incrementa el número y la intensidad de las tormentas en el Pacífico ${ }^{97}$.

2. En Europa, la disminución de la polución calienta el aire y eso conlleva que llueva más en el Sahel. Ha habido un desplazamiento de las lluvias a causa de la disminución de aerosoles $^{98}$.

\footnotetext{
${ }^{95}$ JÓDAR, F., "Carambolas climáticas", revista Muy Interesante, Extra medio ambiente. Cómo salvar la tierra, G y J España Ediciones, S. L., Madrid, mayo de 2015, p. 9.

${ }^{96}$ Yuan Wang, científico del Jet Propulsion Laboratory at the California Institute of Technology, sugiere que la alta contaminación del aire da como resultado nubes más altas, más densas y precipitaciones más abundantes.

${ }^{97}$ Las partículas que provienen de la combustión del carbón son capturadas y transportadas por los vientos dominantes del Pacífico. Este hollín a gran altura sobre el Pacífico, donde el aire está saturado de vapor de aire, actúa como un núcleo de condensación alrededor del cual se forman las gotas de agua. Cuando esta condensación se produce, se libera calor, que aumenta la energía del sistema en forma de vientos y lluvias más fuertes.

${ }^{98}$ Las partículas de los aerosoles reflejan parte de los rayos solares y, además, favorecen la formación de nubes y gotas que a su vez reflejan más radiación solar. Al disminuir, se refleja menos radiación solar y el aire se calienta, lo que crea un sistema de aspiración que atrae el aire marino cargado de humedad. El cinturón
} 
Estos dos estudios pueden cambiar la perspectiva de cómo se ve y afecta la contaminación atmosférica al cambio climático. Actualmente, la comunidad científica empieza a plantearse si la concentración de $\mathrm{CO}_{2}$ es el factor más importante del aumento de temperatura planetario y si este hecho puede ser el principal causante de que los modelos de predicción de temperatura planetaria estén fallando.

- Las energías renovables marinas: el grado de desarrollo de estas tecnologías, en su mayoría, se encuentra en un estadio embrionario y los trabajos en el mar aumentan los costes de instalación, operación y mantenimiento. En este sentido, los incentivos que el Gobierno británico ofrece por cada $\mathrm{MW} / \mathrm{h}$ que se obtiene en la eólica marina, cifrados en 155 libras esterlinas, no son suficientes para igualarse con la tecnología eólica terrestre, aún un $60 \%$ más económica que la marina ${ }^{99}$. Dicho esto, no queda la menor duda de que algunas tecnologías marinas como la energía eólica marina van a cobrar un gran protagonismo por factores ligados al eventual agotamiento, a medio plazo, de los recursos disponibles en tierra ${ }^{100}$.

En este sentido, cabe aplaudir al Ente Vasco de la Energía, que ha convocado, hasta el 31 de diciembre de $2015^{101}$, ayudas destinadas a inversiones para la demostración y validación de tecnologías energéticas renovables marinas. Son iniciativas como estas las que dan impulso al sector.

\section{A MODO DE CONCLUSIÓN}

Las energías renovables son necesarias para dar el salto hacia la tercera revolución industrial, favorecer el desarrollo sostenible y, así, preservar el medio ambiente y beneficiar

ecuatorial de nubes y lluvias es atraído por el calor.

${ }^{99}$ GARCÍA URETA, A., "Reino Unido: entre la incertidumbre del clima, el desarrollo de futuras infraestructuras y la fractura hidráulica”, p. 186, Observatorio de Políticas Ambientales 2014, Pamplona, Thomson-Aranzadi, 2014.

${ }^{100}$ TORRES LÓPEZ, M. ${ }^{\mathrm{a}}$ y ARANA GARCÍA, E., Energía eólica: cuestiones jurídicas, económicas y ambientales, Civitas Thomson Reuters, Cizur Menor, 2010, p. 349.

${ }^{101}$ Para más información, véase la Resolución 150630. Boletín Oficial del País Vasco, número 151, de 12 de agosto de 2015. Recuperado de http://www.ipyme.org/es-

ES/BBDD/AyudasIncentivos/Paginas/DetalleAyudasIncentivos.aspx $?$ refe $=50743 \& C A U T=\& A D M O=\& T I T U$ $=$ renovables + emergentes $\&$ SECT $=\& S U B S=\& V I G E=$ True $\& P R O V=\& D E S=\& T I P O C O N S U L T A=$ paso $1 \& A B$ IERTA $=$ True $\& O R G A=\& P A G E=1$. 
la economía y la salud de los ciudadanos. Además, son la mejor solución conocida para evitar el uso de tecnologías a gran escala para reducir el cambio climático.

Las energías renovables han avanzado en el 2014 e inicios del 2015 en todo el mundo pese a la bajada del precio del petróleo. Ello se debe a diferentes factores según el país que analicemos. Por ejemplo, y analizando los países con una subida más alta de inversión, en China son necesarias por los problemas de salud que genera la quema de combustibles fósiles para obtener energía eléctrica; en Brasil avanzan gracias a los mecanismos de apoyo; en México su avance se debe a la liberalización del sector eléctrico; en Costa Rica, gracias a las exenciones fiscales; y en Sudáfrica, por la apuesta como país líder del corredor de energía limpia que debe cruzar todo el continente africano.

A nivel europeo, no cabe duda de que la Unión Europea promueve las energías renovables a través de políticas dirigidas a reducir la dependencia energética exterior y las emisiones de gases de efecto invernadero.

$\mathrm{Y}$ en el Estado español se planifica para cumplir los objetivos europeos en esta materia. ¿Dónde está, pues, el problema? Primero, en la influencia del lobby energético para seguir controlando un sector energético de difícil acceso para nuevos productores. Segundo, en el cambio de primas, tarifas y retribuciones para las energías renovables, que da lugar a inseguridad jurídica como consecuencia de un marco regulador cambiante e inestable. Tercero, en las pocas ayudas para las energías renovables embrionarias. Cuarto, en las nuevas políticas que quitan derechos a los productores de energías renovables y que podrían vulnerar algunas directivas europeas (véase en este sentido la nueva propuesta de Real Decreto para el autoconsumo, que, si bien mejora algunas cosas respecto a la propuesta de 2013, aún resulta insuficiente). Quinto, en ser un país donde no se favorecen especialmente las energías renovables en comparación con otros de la Unión Europea. Sexto, en no potenciar un mix energético donde el autoconsumo y el pequeño empresario de la energía renovable tengan un peso importante para favorecer un modelo distributivo de energía. Séptimo, en la constante pugna entre las asociaciones de energías renovables y el Gobierno para dirimir quién es el culpable del déficit tarifario.

La solución va a venir a través de políticas que favorezcan la integración energética de las energías renovables en un modelo energético diverso, con energías renovables y 
convencionales, para crear un mix energético potente que dé garantías en cuanto a la seguridad de suministro.

¿Qué se puede hacer a día de hoy? Elaborar planes directores sectoriales energéticos relativos a la ordenación territorial de las energías renovables en las comunidades autónomas para impulsar el desarrollo de estas energías; y, otra medida aún más importante, analizar, corregir y proponer modificaciones al real decreto sobre el autoconsumo que ayude a los pequeños productores a desarrollar su inversión y fomentar las pequeñas instalaciones. De esta forma, las energías renovables podrán contribuir —aún más- al desarrollo económico, social y ambiental del Estado español.

\section{BIBLIOGRAFÍA}

ABAD CASTELOS, M., Las energías renovables marinas y la riqueza potencial de los océanos: ¿un mar de dudas o un mar de oportunidades?, Bosch, Barcelona, 2013, ISBN: 9788494143526 , p. 250.

ALONSO TIMÓN, A., Sectores regulados: Sector energético, sector del transporte y sector de las telecomunicaciones, Dickinson SL, Madrid, 2014, ISBN: 978-84-9031-985-7, p. 458.

ASOCIACIÓN DE EMPRESAS DE ENERGÍAS RENOVABLES. Nota de prensa de 8 de abril de 2015, Madrid. Recuperado de http://www.appa.es/descargas/20150408_APPA_RECORTES_EERR_2014_VF_8.pdf.

_Estudio del Impacto Macroeconómico de las Energías Renovables en España en 2013, p. 162.

Asociación Europea del Artesanado y de la Pequeña y Mediana Empresa (UEAPME). (2010, febrero). Nota de prensa de 1 de febrero de 2010. Bruselas, p. 2. Recuperado de http://www.ueapme.com/IMG/pdf/110201_joint_pr_third_industrial_revolution.pdf.

BENAVENTE, Rocío, "El Gobierno suaviza el borrador tras las crítica”, El confidencial, agosto de 2015. Recuperado de http://www.elconfidencial.com/tecnologia/2015-0806/chasco-para-soria-el-gobierno-no-aprobara-el-decreto-de-autoconsumo-hastaseptiembre_957061/. 
Berkeley Earth. (2015, agosto). Air Pollution Overview. Recuperado de http://berkeleyearth.org/air-pollution-overview/

BLASCO HEDO, E., "Libro verde sobre un marco para las políticas de clima y energía en 2030”, Revista Aranzadi de Derecho Ambiental, núm. 25, mayo-agosto 2013, pp. 351-372.

BLESA MARTÍNEZ, B., "Nuevas tecnologías que contribuyen a mitigar el cambio climático: las instalaciones sostenibles en el mar territorial", Revista Aranzadi de Derecho Ambiental, núm. 18, 2011, pp. 341-354.

CHAPARRO, L., "Ciudades ecológicas”, revista Muy Interesante, Extra medio ambiente. Cómo salvar la tierra, G y J España Ediciones, S. L., Madrid, mayo de 2015, pp. 32-45.

Clúster de la energía (2015, febrero). La Comisión Europea investiga a España por saltarse a la torera la prioridad de despacho de las renovables. Recuperado de http://www.energiaextremadura.org/sala-de-prensa/semana-de-las-energias-renovables-del2-al-4-de-marzo/.

Comisión Europea. (2015, julio). Press release. Transforming Europe’s energy system, Commission's energy summer package leads the way Brussels, 15 July 2015. Recuperado de http://europa.eu/rapid/press-release_IP-15-5358_en.htm.

COMISIÓN NACIONAL DE LOS MERCADOS Y LA COMPETENCIA, “Informe sobre la propuesta de orden por la que se determinan los peajes de acceso de energía eléctrica para 2015", IPN/DE/0014/14 de 11 de diciembre de 2014, p. 60.

—_Informe sobre los resultados de la liquidación provisional 13 de 2014 de la retribución de las instalaciones de producción de energías renovables, cogeneración y residuos”, 17 de marzo de 2015, p. 13.

CONSEJO DE MINISTROS DE ESPAÑA, Programa Nacional de Reformas del Reino de España 2015, Madrid, mayo de 2015, p. 286.

Cruz Peña, Juan. (2014, septiembre). Cómo será la economía del futuro. J Rifkin: "El capitalismo estará abocado a desaparecer en 35 años”. Recuperado en junio de 2015, de http://www.finanzas.com/noticias/economia/20140922/rifkin-capitalismo-estara-avocado2758208.html.

DAGANDO, J.M., "Cómo hackear el clima", revista Muy Interesante, Extra medio ambiente. Cómo salvar la tierra, G y J España Ediciones, S. L., Madrid, mayo de 2015, pp. 94-98. 
DOMINGO LÓPEZ, E., Régimen jurídico de las energías renovables y la cogeneración eléctrica, Madrid, Ministerio de Administraciones Públicas, 2000, ISBN: 84-7088-692-4, p. 397.

Efinétika blog. (2014, junio). RD 413/2014: Viajando atrás en el tiempo, la magia de la retroactividad. Recuperado en mayo de 2015 de https://efinetika.wordpress.com/2014/06/13/rd-4132014-viajando-atras-en-el-tiempo-lamagia-de-la-retroactividad/.

Endesa. (2015, mayo). Generación distribuida. Recuperado de http://www.endesaeduca.com/Endesa_educa/recursos-interactivos/smart-city/generaciondistribuida.

Energía oscura. (2015, mayo). Mercado diario. Recuperado de http://www.energiaoscura.es/como-se-fijan-los-precios/mercado-diario/.

Equipo de redacción de Energías Renovables. (2015, marzo). Los buses de la línea 73 de Estocolmo se recargarán en seis minutos. Recuperado de http:/www.energiasrenovables.com/articulo/los-buses-de-la-linea-73-de-20150330

FACUA-Consumidores en Acción. (2015, agosto). Tarifazo Eléctrico. Un 76\% más de luz en 10 años. Recuperado de https://www.facua.org/es/noticia.php?Id=9594.

Frankfurt School. (2015). FS-UNEP Collaborating Centre. Global Trends in Renewable Energy Investment 2015. En el noveno reporte anual PNUMA "Tendencias Globales en la Inversión de Energías Renovables”, p. 4. Recuperado de http://www.fs-unep-centre.org.

Fundación Vida Sostenible. (2014, marzo). Contaminación atmosférica en China. Recuperado de http://www.vidasostenible.org/informes/contaminacion-atmosferica-enchina/.

GARCÍA URETA, A., "Reino Unido: entre la incertidumbre del clima, el desarrollo de futuras infraestructuras y la fractura hidráulica", Observatorio de Políticas Ambientales 2014, Pamplona, Thomson-Aranzadi, 2014, pp. 181-204.

GONZÁlEZ PÉREZ, J., Comentarios a la ley de suelo ( $3^{\mathrm{a}}$ ed.), Civitas Ediciones, Madrid, 2015, ISBN 9788447048786, p. 1537.

Instituto para la Diversificación y Ahorro de la Energía. Plan de Energías Renovables (PER) 2011-2020. (2011, noviembre). Madrid. Recuperado de 
http://www.idae.es/uploads/documentos/documentos_11227_PER_20112020_def_93c624ab.pdf.

Instituto Español de Comercio Exterior (ICEX). España Exportación e Inversiones. (2015, marzo). India: la inversión en energía limpia superará los 8.820 millones de euros en 2015. Recuperado de http://www.icex.es/icex/es/Navegacion-zona-contacto/revista-elexportador/noticias/NEW2015368909.htm.

International Energy Agency (OCDE/IEA). Energy Technology Perspectives 2014 Executive Summary - Spanish version, mayo de 2015, París, p. 18.

J\&A Garrigues, S.L.P. (2013, febrero). Aprobado nuevo Real Decreto-Ley para contener el déficit tarifario. Recuperado en mayo de 2015, de http:/www.garrigues.com/es/Publicaciones/Alertas/Paginas/Aprobado-un-nuevo-Real-

Decreto-Ley-para-contener-el-deficit-tarifario.aspx.

JÓDAR, F., “Carambolas climáticas”, revista Muy Interesante, Extra medio ambiente. Cómo salvar la tierra, G y J España Ediciones, S. L., Madrid, mayo de 2015, pp. 8-11.

LÓPEZ SAKO, J., Regulación y autorización de los parques eólicos, Aranzadi, Cizur Menor, 2008, ISBN: 978-84-470-3108-5, p. 636.

MARTÍN GALLEGO, M., "La electricidad, clave de la política energética", Temas para el debate, 236, julio de 2014, pp. 21-24.

MCCRONE, A (coord.) et ál., Global Trends in Renewable Energy Investment 2015, Frankfurt School UNEP Centre for Climate \& Sustainable Energy Finance, p. 86.

MEDIA VILLA, D., "SOS: el mundo se derrite", revista Muy Interesante, Extra medio ambiente. Cómo salvar la tierra, G y J España Ediciones, S. L., Madrid, mayo de 2015, pp. 12-17.

MENDOZA LOSANA, A., “Adiós al régimen especial de retribución de instalaciones de producción a partir de tecnologías renovables, cogeneración y residuos en la nueva ley 24/2013, del sector eléctrico”, Noticias Breves, enero de 2014, Gómez - Acebo \& Pombo, p. 5.

Merino, Luis. (2012, enero). Dinamarca, a por todas en renovables. Recuperado en septiembre de 2015. Recuperado de http:/www.energiasrenovables.com/articulo/dinamarca-a-por-todas-en-renovables. 
MINISTERIO DE INDUSTRIA, ENERGÍA Y TURISMO, SECRETARÍA DE ESTADO

DE ENERGÍA, "Informe sobre las medidas de actuación de ahorro y eficiencia energética en cumplimiento del artículo 7”, Madrid, 5 de junio de 2014, p. 54.

MORA RUIZ, M., "La ordenación jurídico-administrativa de las energías renovables como pieza clave en la lucha contra el cambio climático: ¿un sector en crisis?”, Actualidad jurídica ambiental, febrero de 2014, p. 22.

NACIONES UNIDAS, "Declaración de la Conferencia de las Naciones Unidas sobre el Medio Humano", Estocolmo, 5 a 16 de junio de 1972.

Navarro, Conrado y López, Juan. Papeles FAES número 178, febrero 2015. El “consumidor generador": implicaciones del autoconsumo en el sistema eléctrico, p. 26. Recuperado de http://www.fundacionfaes.org/file_upload/publication/pdf/20150216113345el_consumido r_generador_implicaciones_del_autoconsumo_en_el_sistema_electrico.pdf.

NOCEDA, Miguel Ángel, "Pros y contras del autoconsumo eléctrico”, El País, Madrid, junio de 2015. Recuperado de http://economia.elpais.com/economia/2015/06/24/actualidad/1435163869_581409.html.

Observa el mercado eléctrico. (2015, mayo). Falacias del mercado eléctrico. Recuperado de http://www.observaelmercadoelectrico.net/Entiende/index45.html\#go_index.

Page, David. (2014, septiembre). España se hunde en el ranking mundial de mejores países para invertir en renovables. Madrid. Recuperado en junio de 2015, de http://www.expansion.com/2014/09/24/empresas/energia/1411571177.html.

Parlamento Europeo. Energy roadmap 2050, a future with energy, Motion for a European Parliament resolution: on the Energy roadmap 2050, a future with energy (2012/2103(INI)), (2013, febrero).

PEREIRA BLANCO, M., "Las energías renovables: ¿es posible hablar de un derecho energético ambiental? Elementos para una discusión”, Jurídicas CUC, 2015, pp. 233-254.

Pérez Rodríguez, Daniel. (2014, noviembre). El derecho a la prioridad de despacho peligra en España. El Blog de la Energía Sostenible. Recuperado de http:/www.blogenergiasostenible.com/derecho-prioridad-despacho-peligra-espana/ PONT CASTEJÓN, I. y NIETO MORENO, J., “Actuación ambiental del Estado: planificación hidrológica, política energética y calidad del aire", Observatorio de Políticas Ambientales 2014, Thomson-Aranzadi, Pamplona, 2014, pp. 249-266. 
QUINTANA LÓPEZ, T., "El régimen jurídico de la energía eólica. Referencia a Castilla y León”, Revista de estudios de la administración local, núm. 291, 2003, ISBN 1578-4568, pp. 961-985.

RASO, Concha, "América Latina, el nuevo mercado de las renovables", elEconomista.es, julio de 2015.2 Recuperado de http://www.eleconomista.es/energia/noticias/6906817/07/15/America-Latina-el-nuevomercado-de-las-renovables.html\#Kku8xEiOFf2xlh95.

RAFAEL ZANONI, J., ¿¿Qué pueden hacer las políticas energéticas por la integración?”, Revista Mexicana de Política Exterior, Instituto Matías Romero, octubre de 2005, México, pp. 176-185.

RICO, J., "Un futuro cien por cien renovable", revista Muy Interesante, Extra medio ambiente. Cómo salvar la tierra, G y J España Ediciones, S. L., Madrid, mayo de 2015, pp. $52-57$.

ROCA, Ramón, "Los murcianos, los primeros autoconsumidores españoles con balance neto que no pagarán el impuesto al sol”, El periódico de la energia.com, mayo de 2015. Recuperado de http://elperiodicodelaenergia.com/los-murcianos-los-primerosautoconsumidores-espanoles-con-balance-neto-que-no-pagaran-el-impuesto-al-sol/.

Rodrigo, Carlos. (2014, junio). Cinco claves para entender la problemática sobre las primas a las renovables. Recuperado en mayo de 2015, de http://blogs.hoy.es/eneltintero/2014/06/10/cinco-claves-para-entender-la-problematicasobre-las-primas-a-las-renovables/.

ROLDÁN VILORIA, J. y TOLEDANO, J. (coord.), Energías renovables: lo que hay que saber, Paraninfo, Madrid, 2013, ISBN: 9788428329682, p. 220.

RUIZ OLMO, I., "Las renovables ante los recientes cambios normativos: el episodio jurisprudencial del RD 1565/2010, que modifica la tarifa retributiva de la energía fotovoltaica", Actualidad jurídica ambiental, marzo de 2014, p. 28.

Salas, Pep. (2015, junio). Nou esborrany de Reial Decret sobre Autoconsum: un nou pas enrere. Recuperado de http://www.smartgrid.cat/index.php/smartgrids/126-nou-esborranyde-reial-decret-sobre-autoconsum-pitjor-impossible.

SALINAS ALCEGA, S., El cambio climático: entre cooperación y conflicto, Aranzadi, 2014, ISBN 9788490596869, p. 285. 
TORRES LÓPEZ, M. ${ }^{\mathrm{a}}$ y ARANA GARCÍA, E., Energía eólica: cuestiones jurídicas, económicas y ambientales, Civitas Thomson Reuters, Cizur Menor, 2010, p. 493.

VILLORIA, M. (dir.), REVUELTA, A. (coord.) et ál., "Evaluación del lobby en España: Análisis y propuestas”, Transparencia Internacional, Madrid, 2015, p. 122.

Wambi, Michael. (2015, enero). EuroXpress. El desarrollo de África pasa por las energías renovables. Recuperado de http://www.euroxpress.es/index.php/noticias/2015/1/22/eldesarrollo-de-africa-pasa-por-las-energias-renovables/. 